\title{
SEGURANÇA HÍDRICA PARA O CAPITAL E DESPOJO MÚLTIPLE EM CONTEXTOS DE ESCASSEZ: ANÁLISE CRÍTICA SOBRE O NOVO CAMINHO DAS ÁGUAS NO ESTADO DA PARAÍBA, BRASIL
}

\author{
Hugo Belarmino de Morais \\ Universidade Federal da Paraíba (UFPB) \\ Universidade Federal Fluminense (UFF)
}

\begin{abstract}
RESUMO
Neste artigo analisa-se novos processos de (re)territorialização ligados à construção de obras hídricas no Nordeste do Brasil, chamado "Canal Acauã-Araçagi", situado no Estado da Paraíba (Região Nordeste). Para tal reflexão, busca-se apresentar o território estudado e seu novo contexto, caracterizado por um novo momento de intervenções estatais justificadas pela necessidade de resolver problemas históricos de escassez naquela região e as modificações que a própria pesquisa sofreu neste processo dinâmico de investigar a realidade social. Em segundo lugar apresentamos alguns pressupostos da investigação ancorados na teoria crítica e na ecologia política e o conceito de despojo multiple, para depois discutir criticamente alguns dados coletados nas atividades de campo realizadas no mês de Julho de 2018 na Paraíba, que chamamos de "novo caminho das águas". Ao final, recorremos ao termo "segurança hídrica para o capital" para caracterizar os objetivos da obra, que contradiz o discurso oficial sobre sua necessidade/importância para o abastecimento humano em uma região com problemas de acesso e uso da água, apontando para um cenário de ampliação de conflitos territoriais naquela região.
\end{abstract}

Palavras-chave: Conflitos socioambientais. Despojo. Cercamentos; Água.

\section{WATER SECURITY FOR CAPITALAND DESPOJO MÚLTIPLE IN CONTEXTS OF SHOTAGE: A CRITICAL ANALYSIS ON THE NEW WATER PATH IN THE STATE OF PARAÍBA, BRAZIL}

\begin{abstract}
This article analyzes the new processes of (re)territorialization caused by the construction of water enterprises in the Northeast of Brazil, called "Canal Acauã-Araçagi", in the State of Paraíba (Northeast Region). For this work, it is sought to present the studied territory and its new context, characterized by a new moment of state interventions related with the need to "solve" historical problems of water shortage in that region and the changes that the research suffered in this dynamic process of social investigation. Second, we present some research points based in the critical theory and political ecology and the concept of despojo multiple, to discuss some of the data collected in the research activities in July 2018 in Paraíba, which we call the "new waters ways". In the end, we used the term "water security for capital" to characterize the objectives of the enterprise, which contradicts the official discourse about its necessity/importance, highlighting the current scenario of expansion of territorial conflicts in that region.
\end{abstract}

Keywords: Socioenviromental conflicts. Dispossession. Enclosures. Water. 


\section{INTRODUÇÃO}

Neste artigo pretendemos apresentar algumas das reflexões que estamos desenvolvendo na tese de doutoramento em curso no Programa de Pós-graduação em Sociologia e Direito da UFF, que discute processos de territorialização e conflitos socioambientais decorrentes da construção de grandes obras hídricas no Estado da Paraíba, Nordeste Brasileiro, tendo como experiência empírica a Barragem de Acauã e o Canal Acauã-Araçagi.

Buscaremos apresentar, primeiramente, alguns aspectos gerais sobre o território estudado e que sofreu alterações e ampliações significativas tanto do ponto de vista teórico quanto empírico. Partimos de alguns aspectos iniciais ligados à nossa atividade na assessoria jurídica popular no caso da Barragem de Acauã para construir o projeto de pesquisa do doutorado, no entanto a própria realidade como "um todo caótico" e com "múltiplas determinações" foi exigindo do pesquisador alterações, sobretudo buscando "antecipar" elementos de uma espécie de (re)territorialização do agrohidronegócio no caso estudado como decorrência da construção do Canal Acauã-Araçagi.

Nesta perspectiva assumimos a importância do diálogo crítico do materialismo históricodialético com o pensamento crítico latino-americano e os desafios da pesquisa empírica, a fim de formular novos aportes sociojurídicos provocadores de novos horizontes de sentido e de conhecimento.

Busca-se, então, apontar os aspectos centrais desta "pesquisa em movimento" e conectá-los a algumas categorias críticas da ecologia política e dos clássicos do marxismo, mas sempre evitando perspectivas formalistas e/ou estruturalistas de construção deste conhecimento sociojurídico.

Para isso, iremos apresentar elementos da pesquisa de campo realizada em meados de julho e agosto de 2018, partindo da Barragem de Acauã até o canteiro de obras do Canal Acauã-Araçagi, que intitulamos de "novo caminho das águas", no qual foi possível dimensionar, junto às populações locais - atingidos e atingidas - alguns aspectos relevantes sobre o andamento da obra, seus objetivos e impactos, dentro de um contexto de "produção de escassez" hídrica.

Por fim, apontamos algumas das sínteses parciais desenvolvidas até aqui, muito mais como resultado da instigação da pesquisa empírica, que nos permitem apontar um cenário preliminar de "segurança hídrica para o capital" como resultado conflituoso deste "novo caminho das águas" na Paraíba. 


\section{1. ÁGUAS E PESQUISA EM MOVIMENTO: ALGUNS ASPECTOS TEÓRICO- METODOLÓGICOS ${ }^{1}$ DA INVESTIGAÇÃO}

Do ponto de vista empírico esta pesquisa se propõe a analisar - em especial diálogo entre os campos da sociologia, do direito e da geografia - os novos processos e conflitos hidrícoterritoriais decorrentes da "integração" de três grandes obras na Paraíba: o Eixo Leste da Transposição do São Francisco, a Barragem de Acauã e o Canal Acauã-Araçagi.

$\mathrm{Na}$ investigação, partimos da Barragem de Acauã, pois esta obra além de ser cronologicamente anterior - a construção da Barragem foi realizada no final dos anos 1990 até meados de 2002 - foi responsável por três fatos marcantes que definiram a construção inicial do projeto de pesquisa.

Em primeiro lugar, a Barragem de Acauã foi responsável pela remoção forçada de cerca de 900 famílias que viviam às margens do Rio Paraíba e que com este Rio ${ }^{2}$ (re)produziam suas condições de existência, como moradores rurais, ribeirinhos e campesinos ${ }^{3}$. A construção desta Barragem já foi objeto de diversos conflitos e denúncias e continua até hoje como um caso emblemático de violações de direitos humanos em matéria de barragens no Brasil, conforme Relatório oficial produzido pelo Conselho de Defesa dos Direitos da Pessoa Humana em 2010 (BRASIL 2010), inclusive com o alagamento de dois cemitérios das comunidades ${ }^{4}$.

Por fim, cabe ressaltar que este processo de violação de direitos e desterritorialização fez emergir a própria presença do Movimento de Atingidos por Barragens (MAB) na Paraíba, que até hoje luta por reparações e melhoria nas condições de vida das populações atingidas, reafirmando uma questão para nós muito importante sobre o "duplo movimento": resultado de diversas conjunturas e nem sempre de forma orgânica ao longo do tempo, cada processo de

\footnotetext{
${ }^{1}$ Estas discussões aqui apresentadas - com diversas modificações e acréscimos - fizeram parte do texto-projeto de qualificação para o doutorado do pesquisador, apresentado no PPGSD-UFF, intitulado "A NARRATIVA DOS PÁSSAROS E OS NOVOS CERCAMENTOS: um estudo de caso sobre os caminhos das águas e os conflitos territoriais a partir da Barragem de Acauã na Paraíba".

${ }^{2}$ Afirmamos com este Rio desde uma abordagem a partir da ecologia política, em virtude da nossa compreensão de que os processos humanos e não humanos estão correlacionados e interdependentes para definir as condições de reprodução da vida.

${ }^{3}$ A partir das inquietações trazidas pelo Seminário Entramados Comunitários y formas de lo político - o que tivemos a oportunidade de integrar no processo de doutorado sanduíche na BUAP em Puebla, no México - decidimos acompanhar a reflexão ali presente e não mais utilizar o termo meios de produção, mas ampliar este temos para meios ou condições de existência, pois, de fato, é disto que se trata quando pensamos os processos sociais na atual fase de "novos cercamentos" no neoliberalismo. Para mais, ver Mina Navarro Trujillo (2019).

${ }^{4}$ Afirmamos a questão do alagamento dos cemitérios porque no momento da construção de nosso projeto de doutorado, em meados de 2015, estes cemitérios reapareceram após um contexto de seis anos de seca e baixa pluviosidade na região da Barragem. Este reaparecimento no mesmo momento em que as obras do Canal Acauã-Araçagi estavam sendo iniciadas, comemoradas e desenvolvidas representou um ponto significativo na escolha dos conflitos de Acauã para a tese, partindo da figura ao mesmo tempo de pesquisador-militante e assessor jurídico popular.
} 
cercamento/expropriação também acaba por engendrar processos de luta e organização contra os cercamentos.

Conforme afirma Vainer, o principal efeito não desejado dos Estudos de Impacto Ambiental (EIA's) em grandes empreendimentos como as barragens é a "ocorrência" de resistências e lutas, pois "a impactologia ad hoc dos experts continua sendo incapaz de prever as lutas, a resistência, a organização das populações" (VAINER 2004:1). Desta forma, foram os conflitos decorrentes da construção da Barragem de Acauã em seus contextos atuais que moveram, inicialmente, os interesses desta pesquisa.

Sobre o Eixo Leste da Transposição do São Francisco existe uma vasta literatura ${ }^{5}$ que apontava - e ainda aponta - um conjunto múltiplo de conflitos e narrativas distintas sobre a viabilidade e necessidade da obra. O que necessitamos apontar, para os fins deste artigo, é que no curso desta pesquisa de doutorado as obras do Eixo Leste foram "concluídas"6 e no dia 19 de março de 2017 ocorreu na cidade de Monteiro-PB a chamada "inauguração popular" do Eixo Leste da Transposição do Rio São Francisco. Esta atividade serviu para celebrar a chegada daquelas águas na Paraíba - após percorrer cerca de 270 quilômetros de extensão pelos Estados da Bahia e Pernambuco - com um grande ato político que contou com a presença do ex-Presidente Lula e a Presidenta Dilma Rousseff.

Ressalte-se que tal inauguração se deu dentro do contexto de disputas políticas após o golpe de Estado que depôs a Presidenta. O tom de toda a atividade foi de que a "paternidade" da obra não poderia ser remetida à outra pessoa que não ao ex-Presidente Lula e que a "maternidade" da obra seria da Presidenta Dilma, numa estratégia discursiva voltada à produção do consenso sobre a importância/necessidade/legitimidade da Transposição para resolver definitivamente os problemas hídricos da Paraíba. Segundo os organizadores, o ato contou com a presença de 50 mil pessoas.

\footnotetext{
${ }^{5}$ Consultar, por todos, o livro de Juliana Neves Barros intitulado O desencantamento das águas no sertão. Crenças, descrenças e mobilização social no Projeto de Transposição do Rio São Francisco. Este trabalho representa um esforço recente na sistematização do referencial bibliográfico sobre o caso da Transposição do Rio São Francisco e os conflitos decorrentes da realização daquela obra. Ver bibliografia.

${ }^{6}$ Há uma dificuldade atual de definir a "conclusão" das obras do Eixo Leste da Transposição: por um lado, pelo conjunto amplo de obras complementares que eram previstas e não estão sendo realizadas e, por outro, pela nossa compreensão de que uma grande obra hídrica, do ponto de vista sociojurídico e ambiental, nunca termina. O que pode terminar são as obras de engenharia e infraestrutura - com seus impactos correlatos - mas partindo de uma compreensão sociológica mais ampliada essas obras só começam, nunca terminam. Podemos citar diversos exemplos desta "incompletude planejada": a situação das águas do São Francisco continua extremamente alarmante, com relatos da sua perda de vazão no Estado de Pernambuco, Alagoas e Sergipe; a ocorrência de chuvas de forma mais ampliada no ano de 2019 nos "estados receptores" das águas indica, ao menos para este ano, a desnecessidade de deslocamento das águas para fins de abastecimento humano e dessedentação animal; a discussão sobre a privatização do sistema Eletrobrás - incluída aí a Companhia Hidrelétrica do São Francisco (CHESF) - e, inclusive, a privatização da própria gestão da Transposição, estão em pauta; as obras complementares em cada Estado Nordestino que receberá as águas da Transposição também são elementos de uma continuidade e complexidade sobre o que poderíamos chamar de "obras concluídas".
} 
Após esta inauguração e a situação de emergência do município de Campina Grande-PB, as águas foram direcionadas para o Açude Boqueirão - responsável por todo o abastecimento da região metropolitana daquela cidade - e foram comemoradas como o primeiro grande resultado concreto da Transposição do São Francisco na Paraíba.

Assim, percebemos e recebemos as contradições inerentes ao Projeto da Transposição como dados objetivos importantes desta pesquisa, mas não pretendemos retornar a estes conflitos, dadas as novas complexidades inerentes aos "desdobramentos" da Transposição no caso paraibano, elemento "novo" dentro desta conjuntura. Por tudo isso, ressaltamos que em nossa pesquisa partimos da constatação de que o histórico das obras da Transposição e os conflitos socioambientais produzidos devem servir de experiência histórica e horizonte sobre o que poderá ocorrer, ainda que no caso concreto não tenhamos optado por realizar um recorte territorial que englobe as obras da Transposição na Paraíba.

Sobre a terceira obra - o Canal Acauã-Araçagi ou Canal das Vertentes Litorâneas preferimos discutir seus elementos em capítulo específico sobre o nosso processo de pesquisa de campo ocorrido no ano 2018. Assim, para fechar esta sucinta apresentação sobre o território estudado apresentaremos basicamente a localização destes pontos de interesse. O Mapa a seguir indica a localização geográfica dos pontos de interesse para esta pesquisa:

Figura 1: Mapa da Paraíba e do possível "caminho das águas” desde a Transposição até a Barragem de Acauã.

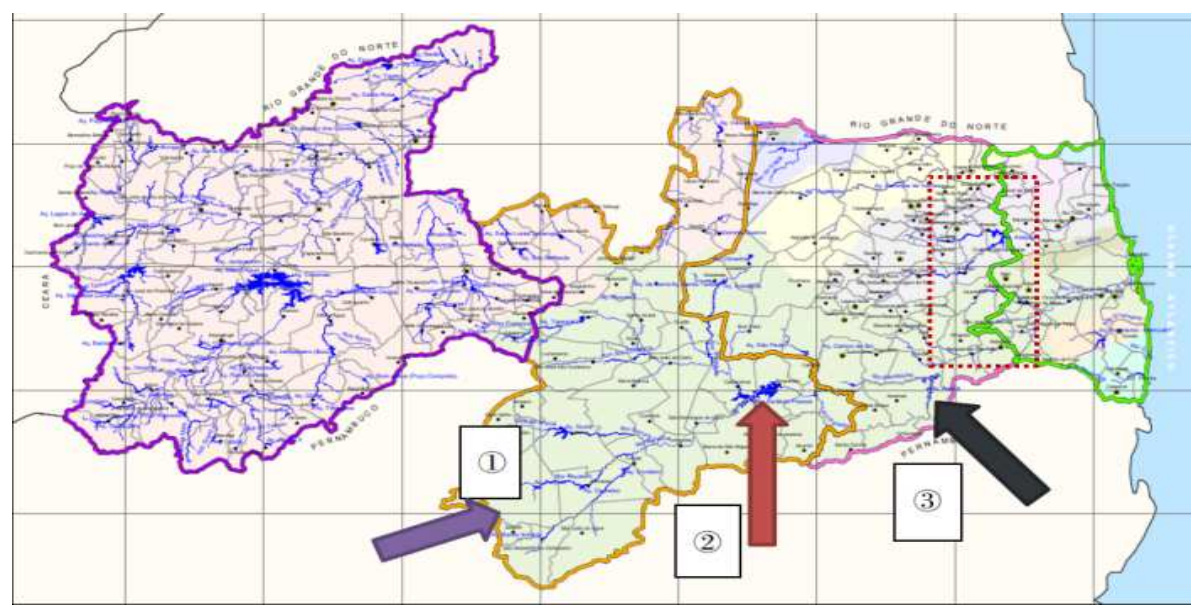

Fonte: Aesa, 2018. Editada pelo Pesquisador (2018).

No caso do eixo leste da Transposição, as águas entram na Paraíba a partir da cidade de Monteiro-PB (número 1 - seta de cor roxa) e seguem o curso pelo Rio Paraíba até o Açude de Boqueirão (número 2 - seta vermelha), que abastece a cidade de Campina Grande e toda a sua microrregião. O planejamento hídrico do Estado da Paraíba é de que as águas retornem novamente 
para a calha do Rio Paraíba até chegar à Barragem de Acauã (número 3 - seta preta) e, mais especificamente nas proximidades da comunidade de Melancia - outra comunidade atingida pela Barragem de Acauã - existe uma tomada d'água do Canal Acauã-Araçagi, que é o nosso objeto principal neste artigo. Este Canal, chamado de "Transposição da Paraíba" ou "Canal das vertentes litorâneas", é o principal elemento "novo" desde o início da pesquisa de doutorado e objeto, portanto, de novas inquietações e discussões. Está apontado no mapa dentro do traçado pontilhado de cor vermelha.

Assim, estamos tratando de uma espécie de "novo caminho das águas", objeto privilegiado da reflexão que se pretende fazer na pesquisa e que já conta com dados iniciais mapeados e cartografados, como veremos nos próximos capítulos.

Chamamos de "novo caminho das águas" pois o território analisado está em processo de transformação decorrente da expectativa - e parcial concretização - da utilização dessas novas águas tanto para abastecimento humano quanto para atividades econômicas, vinculando-se à uma nova fase de desenvolvimento na Paraíba, conforme o discurso oficial.

Esta singularidade é tratada aqui, sociologicamente, como uma novidade empírica com repercussões socioeconômicas, geográficas e jurídicas, sobretudo em virtude da bifurcação realizada pelo Canal supracitado, que segue um caminho distinto - e artificial - em direção ao litoral norte do Estado, microrregião que já tem certa oferta hídrica e reconhecida pela presença forte do agrohidronegócio, sobretudo de cana-de-açúcar. Uma bifurcação, pois, carregada de elementos importantes a partir de uma mirada da ecologia política latinoamericana.

Nos permitimos enxergar, neste contexto, uma espécie de "pesquisa em movimento", que tenta acompanhar este "caminho das águas" até onde for possível para, a partir daí, construir elementos de síntese e de compreensão.

Assim, queremos apontar com esta caracterização do território e da pesquisa sua essência dialética, encarados como processo e movimento e não como estrutura fixa e dado "morto"7. Reportamos e refletimos que essa característica não se deve somente ao método utilizado e suas modulações, mas à centralidade da água e seus conflitos territoriais, que exigem esta dimensão ao mesmo tempo conflituosa e dinâmica.

A reflexão, pois, anteriormente centrada na discussão sobre barragens - compreendidas como uma forma singular de "cercamento" de terras e águas - ampliou-se para uma reflexão sobre

\footnotetext{
7 Ao nos referirmos, aqui, a dado "morto" estamos nos contrapondo a partir de uma visão crítica sobre as pesquisas empíricas, que, em geral, encaram os dados empíricos como dados ou valores em si, em geral produzindo um empirismo acrítico e pouco afeito às discussões marxistas. Por outro lado, isto não significa desvalorização da empiria, como se a realidade pudesse ser analisada e conformada a priorísticamente por um conjunto teórico. É a dupla negação, da realidade em relação à teoria e da teoria em relação à realidade, que vimos trabalhando a partir da chamada sociologia viva. Para mais, ver Ribeiro et al. 2018.
} 
os conflitos socioambientais ligados ao controle, acesso e uso das águas no contexto nordestino a partir das grandes obras hídricas. Desta forma, portanto, o território objeto desta investigação se ampliou significativamente, demandando a reorientação das atividades de campo a fim de percorrer os atuais caminhos do Canal Acauã-Araçagi, com a finalidade de identificar, cartografar e analisar estes novos caminhos e seus eventuais conflitos, partindo da realidade já experienciada pelos atingidos de Acauã.

Assim como as águas, que fluem e são essencialmente movimento, podemos descrever que nossa pesquisa se caracteriza por este movimento, como se a água estivesse, a todo tempo, reafirmando o seu estado vivo, para além dos estados "tradicionais" da matéria, como nos ensina Porto-Gonçalves: “(...) a água é fluxo, movimento, circulação. Portanto, por ela e com ela flui a vida e, assim, o ser vivo não se relaciona com a água: ele é água. É como se a vida fosse um outro estado da matéria água, além do líquido, do sólido e do gasoso - estado vivo" (2008: 120).

Afinal, assim como a vida e sendo a própria vida, a água acaba por condicionar os movimentos também das pesquisas que se pretendem realizar sobre ela e com ela, como tem ocorrido nesta pesquisa.

Antes, porém, de apontar alguns dados da pesquisa empírica realizada, acreditamos ser importante contextualizar algumas questões sobre os conflitos envolvendo a água em seu sentido mais amplo a fim de produzir uma análise que relacione teoria e empiria. Neste sentido, no próximo tópico iremos discutir algumas categorias importantes que foram sendo incorporadas à pesquisa, sobretudo a partir de estudos de ecologia política.

Estes estudos foram - e são - importantes para construir um enquadramento teórico preliminar, sobre os desafios e dificuldades para pensar as lutas por terra e água num contexto de reprodução ampliada do capital, como veremos.

\section{O "NOVO CAMINHO DAS ÁGUAS" NA PARAÍBA À LUZ DA ECOLOGIA POLÍTICA: PRODUÇÃO DA ESCASSEZ E DESPOJO MÚLTIPLE EM OBRAS HÍDRICAS NO SEMIÁRIDO}

No Brasil e na América Latina, multiplicam-se os casos de conflitos envolvendo água. Em geral, estes conflitos não podem ser dissociados das lutas por terra e território, embora assumam, em cada configuração e contexto, diferenças qualitativas importantes.

Estes estudos apontam que está em curso um novo processo de "cercamentos das terras e das águas" em nível global. Isto porque a demanda por "recursos naturais" tem aumentado vertiginosamente sobretudo após a crise capitalista global - que ainda perdura - de 2008. Este 
processo se caracteriza, em sentido geral, por uma nova corrida por terras e águas, que uma literatura recente têm chamado de land e water grabbing. Para buscar liquidez e lastro de segurança diante de flutuações derivadas do processo de financeirização da economia e também da agricultura, acumulam-se relatos de um processo ampliado de compra - ou outros mecanismos de controle sobre posse e uso - de terras e outros bens naturais, em especial nos países do chamado Sul Global e América Latina (BORRAS JR et al. 2012) e no caso brasileiro não é diferente.

Embora não seja possível aprofundar este debate aqui ${ }^{8}$, é importante nos posicionar - a partir de autores do pensamento crítico latinoamericano - que defendem e retiram consequências práticas da continuidade da acumulação originária.

Este processo global de reprodução ampliada do capital, além de reforçar conflitividades socioambientais, é a demonstração cabal da essência destrutiva, espoliadora e violenta do capitalismo mesmo em suas fases mais avançadas, necessitando sempre lutar contra todas as formas não-capitalistas ou não-plenamente capitalistas de (re)produção social, contra a economia camponesa e contra a economia natural, como já nos afirmava Rosa Luxemburgo - considerada pela literatura a precursora dos debates atuais sobre este processo de acumulação por espoliação ainda no início do século XX.

O capitalismo sempre associa meios econômicos fundados na exploração capital-trabalho com meios extra-econômicos, avançando sobre fronteiras e formas de produção não-capitalistas para garantir sua reprodução ampliada. Isto porque, como afirma a autora, na realidade, "a violência política é também aqui somente o veículo do processo econômico; ambos os aspectos da acumulação do capital estão organicamente ligados pelas condições de reprodução do capital, apenas juntos fornecem a carreira histórica do Capital” (Luxemburgo 1984:86-87).

Deste debate teórico-prático sobre os processos de expropriação da natureza humana e não humana e suas consequências, optamos por utilizar um conceito tanto mais ampliado quanto possível, dadas as repercussões para nosso trabalho empírico. Partindo de De Angelis e sua caracterização da separação - compreendida a partir da Crítica da Economia Política de Marx sobre o processo de cisão entre produtores e seus meios de existência, condição essencial para

\footnotetext{
${ }^{8}$ Em outra oportunidade já realizamos uma revisão teórica sobre a questão dos cercamentos das águas (MORAIS 2017), embora estejamos em processo de (re)construção de nossa perspectiva teórica a partir da literatura latinoamericana em virtude das confluências advindas de nosso estágio de doutorado sanduíche (PDSE) no Seminario Permanente "Entramados comunitarios y formas de lo político" na Benemérita Universidad Autónoma de Puebla, em Puebla, México. Uma boa revisão sobre este debate e sobre as lutas pelo comum que não estão centradas no Estado - que nos influenciou fortemente na reconstrução do objeto da pesquisa - está presente nos livros Luchas por lo común: antagonismo social contra el despojo capitalista de los bienes naturales en México (TRUJILLO 2015), Horizonte comunitario-popular: antagonismo y producción de lo común en América Latina (AGUILAR 2015).
} 
acumulação de capital - Mina Navarro Trujillo apresenta uma forma inovadora de interpretar esse debate, acrescentando novos parâmetros. Sobre o conceito de separação, afirma a autora que:

\begin{abstract}
1) la separación es una condición necesaria del capital para intervenir el tejido de la vida; 2) la separación debilita el control de las y los productores sobre sus medios de existencia; 3 ) la separación oculta y deforma la red de relaciones de interconexión e interdependencia entre todas las formas de vida que, en conjunto habitamos el planeta; y; 4) los procesos de lucha contra las separaciones representan una alternativa para recuperar control sobre los medios de existencia, revertir y resarcir parcialmente los efectos y alteraciones que el capital produce sobre el tejido de la vida. (Trujillo 2019:10)
\end{abstract}

A partir desta síntese, Trujillo formula uma ideia em nossa opinião extremamente fértil e interessante para os propósitos dos trabalhos que discutem conflitos envolvendo água e grandes projetos hídricos, que é o conceito de despojo múltiple. Para caracterizar este processo contemporâneo de "novos cercamentos" desde uma compreensão latinoamericana, defende

\begin{abstract}
que toda separación produce o conlleva a una serie despojos múltiples sobre los ámbitos de vida y medios de existencia. Esto es, en la medida en que el capital produce separaciones, es que cuenta con las condiciones para subsumir el tejido de la vida y por tanto, intervenir y reconfigurar las relaciones entre la vida humana y no humana, transformar la forma y contenido de los metabolismos, despojar medios de vida, pero también capacidades políticas de autodeterminación (Trujillo 2019:10).
\end{abstract}

Estamos em total acordo com a pensadora mexicana. Isto porque não basta reconhecer que estamos numa fase de maior concentração e financeirização da economia mundial e de profunda crise do capital - que se movimenta em busca de terras e águas - além de outros "recursos" na América Latina. É preciso apontar que os diferentes usos desses bens - de forma especulativa ou não - reconfiguram-se e ampliam-se, inclusive em regiões onde historicamente o processo de acumulação era construído a partir de outros moldes, mais “clássicos", como a latifundiarização e a super-exploração do trabalho.

Trata-se, outrossim, de compreender que a apropriação, controle e mercantilização das águas ligadas a este contexto neoliberal não somente é um mecanismo indireto de acumulação. Atualmente no Brasil e na América Latina a água é mecanismo direto e indireto de acumulação, como observa Ioris (2010).

Esses novos componentes ampliam o despojo, tanto da natureza humana e não humana como as capacidades políticas de organização e gestão comunitária dos camponeses, e afetam dramaticamente um conjunto de comunidades, produzindo e reproduzindo novas separações no tecido da vida. Processo que se dá, principalmente, pela prevalência do valor de troca em relação ao valor de uso na própria caracterização da água e dos processos hídricos.

É dentro deste contexto que pensamos a centralidade das obras hídricas no semiárido nordestino (re)produzindo despojos múltiples. Este processo está ligado a pelo menos cinco 
elementos na nossa conjuntura: 1) a relação entre a demanda por água e a produção de commodities agrícolas; 2) a necessária concentração e intensificação de capital interligada à construção de qualquer grande projeto de investimento, como barragens, canais, portos, perímetros irrigados, etc; 3) em nível mundial, o debate sobre a mercantilização e financeirização das águas nos meios urbanos e meios rurais; 4) a discussão sobre a gestão dos recursos hídricos no semiárido reproduzindo uma lógica economicista e gerencialista que em geral despreza a capacidade política e organizativa de campesinos e ribeirinhos sobre os seus meios de existência; 5) os impactos ambientais resultado dessas intervenções sobre os próprios corpos hídricos - rios, lagos, mananciais, fontes minerais, etc. - numa perspectiva "ecocida", ou seja, que protagoniza "assassinatos da natureza" em nome do desenvolvimento.

À luz da ecologia política, por outro lado, a centralidade da água está conectada, também, com o discurso da escassez. Em sentido geral, podemos afirmar que o discurso da escassez se caracteriza pela produção de um certo consenso que naturaliza a falta d'água em diversos contextos vinculando-os a uma generalização e naturalização das responsabilidades "de todos" para superar tais problemas. Como afirma Porto-Gonçalves (2008), há um reducionismo enorme neste debate, que trata a questão hídrica dissociada de um processo social mais amplo - de uma desordem ecológica global - que precisa ser criticada, pois fornece justificativas políticas para o reforço do paradigma da escassez:

Tudo indica que estamos imersos num complexo processo de desordem ecológica que, mesmo diante de maior quantidade de água doce disponível sob a forma líquida, está produzindo um aumento da área desertificada e do número de localidades submetidas a stress hídrico, inclusive em muitas das grandes cidades do mundo. Enfim, é de urna desordem ecológica global que estamos falando e não simplesmente de escassez de água, como vem sendo destacado (Porto-Gonçalves 2008:118) (grifos nossos).

Trata-se, portanto, de um discurso que naturaliza o que é produto histórico específico de uma sociedade construída num determinado modo de produzir e de se reproduzir socialmente. Afirma Ioris:

Como instrumento de legitimação junto à opinião pública, as novas políticas fazem referências simbólicas à escassez de água no Nordeste (na verdade, um problema agrário, muito mais que hidrológico), a conflitos no Oriente Médio (decorrentes de racismo, geopolítica e dominação econômica) ou à poluição dos rios (muito mais um problema de urbanização caótica). Essa centralidade da noção de escassez para a introdução do novo marco regulatório de recursos hídricos não é mera coincidência, mas permite que toda uma racionalidade de viés ainda mais explicitamente capitalista seja sobreposta aos procedimentos de uso e conservação. Porém, escassez e abundância não são conceitos absolutos, mas somente fazem sentido em um contexto social e cultural específico, muitas vezes organizado de forma a permitir o funcionamento de mercados (Harvey, 1973). Assim, a proclamada escassez de recursos hídricos no Brasil contemporâneo é o resultado de um 
processo de exploração do meio ambiente a serviço de um desenvolvimento desigual implantado ao longo de sua história socioeconômica (Ioris 2010:236-237).

Desta forma, o discurso da escassez cumpre um papel ideológico importante nas sociedades capitalistas, que necessitam, por sua própria essência de valorização do valor, de um constante ciclo produtivo - e também reprodutivo - fundado no controle e mercantilização de "bens escassos". Na medida em que se produz um consenso sobre a escassez da água, portanto, esta passa não só a ser concebida como um bem da natureza ou um bem comum, mas antes de tudo um bem de valor econômico ou mercantil.

Ainda que seja inegável a diferença dos conflitos envolvendo água em regiões com altos índices de pluviosidade em comparação com regiões - como a nossa região nordeste - que historicamente se caracterizam pela menor oferta hídrica "natural", não podemos esquecer que tais regiões, exatamente pela centralidade da água na própria conformação de territorialidades camponesas, construíram ao largo do tempo um conjunto de experiências culturais, tecnológicas e simbólicas de convivência com o semiárido, compreendido por Pontes e Maciel como:

\begin{abstract}
uma confluência de ideias resultando de anos de debates baseados na experiência concreta dos habitantes locais, com recentes contribuições acadêmicas e implicações políticas ou legais sobre a relação natureza-sociedade no Nordeste (sobretudo no que tange às secas e à semiaridez). Empregado no sentido lato de modelo, padrão ou exemplo a ser seguido, o paradigma da convivência opõe-se aos métodos convencionais do paradigma hidráulico grandes obras para acumular água - buscando estabelecer novos princípios, normas e práticas orientadoras para uma melhor coexistência das populações com a semiaridez, baseando-se em tecnologias socialmente apropriadas (Maciel e Pontes 2015:15)
\end{abstract}

No caso do Nordeste Brasileiro e, em especial, do semiárido, o discurso da escassez foi responsável, historicamente, pela justificativa da realização de diversas obras para "solucionar" o problema. A história do Nordeste pode ser contada a partir dos conflitos decorrentes de uma racionalidade tecnocrática ligada às oligarquias regionais demandando mais e mais recursos públicos para construção de diversas obras públicas de infra-estrutura hídrica - como açudes, barragens, canais, adutoras, transposições, poços artesianos, etc.

Tais obras, se por um lado cumpriram algum papel importante na criação de infraestruturas para armazenamento e abastecimento de água, em geral estiveram - e até hoje estão - ligadas a um processo de concentração do binômio terra-água nas mãos de poucos e da burocratização da gestão hídrica nas mãos do Estado. Uma espécie de união hídrico-territorial a favor dos grandes em detrimento dos "de baixo".

No nosso caso de estudo esta questão se repete, embora com novas conformações mais “modernas". A construção da barragem no final dos anos 1990 e seus conflitos decorrentes 
continuam vigentes, a luta por reparação aos atingidos da Barragem de Acauã, como afirmamos, é objeto de demandas e lutas por parte do movimento social até hoje.

A esses conflitos já documentados e objeto de reflexões e denúncias, seria possível pensar e cartografar novos conflitos e novas situações de violações de direitos? A construção da Transposição do São Francisco e a "chegada das águas" na Paraíba reconfigura este debate? A construção do Canal Acauã-Araçagi - como obra complementar à Transposição - aponta para novos conflitos, mais uma vez reforçados pelo paradigma da escassez?

Partindo, pois, dessas inquietações instigadas pela realidade - reconfiguradas pelas análises teóricas e ampliadas pela necessidade de estudar o processo atual em movimento - justificamos e organizamos nosso trabalho de campo, realizado entre os dias 27 e 31 de julho de 2018. Intitulamos este trabalho de "novo caminho das águas", o qual descreveremos no próximo capítulo.

\section{ALGUNS DADOS PRELIMINARES ACERCA DA PESQUISA DE CAMPO (JULHO/2018) E A POSSÍVEL CARACTERIZAÇÃO DE UMA SEGURANÇA HÍDRICA PARA O CAPITAL}

Como já vimos detalhando ao longo deste artigo, a investigação sobre os conflitos envolvendo barragens e obras hídricas na Paraíba exigiu do pesquisador a construção de uma estratégia teórico-metodológica para compreender melhor o que está se passando como decorrência das novas obras do Canal Acauã-Araçagi.

Aspecto importante a ser apontado foi o planejamento e a parceria entre o pesquisador e sua orientadora de doutorado na atividade de campo, seguindo o saber-fazer das experiências já consolidadas no âmbito do Observatório Fundiário Fluminense (OBFF) desde sua fundação no início dos anos $2000^{9}$.

Complexificando ainda mais esta estratégia metodológica do caminho das águas, decidimos coletivamente que a presença do movimento social organizado - no caso, do Movimento de Atingidos por Barragens (MAB) - durante todos os dias de percurso no campo era imprescindível. Isto porque não somente era importante cartografar, realizar entrevistas e documentar as atividades, mas contar com a experiência social dos próprios movimentos na leitura desta realidade.

\footnotetext{
${ }^{9}$ Importante ressaltar este saber-fazer consolidado sob a orientação da Profa. Dra. Ana Maria Motta Ribeiro, no qual orientand@s e orientadora partem juntos para a pesquisa de campo ao menos uma vez na condução da pesquisa empírica. Este fato pressupõe disponibilidade e compromisso fora do comum dentro da Academia. Por outro lado, tal experiência demanda uma organização e planejamento ainda mais refinados, haja vista a diversidade e intensidade das visões compartilhadas tanto na construção e coleta de dados quanto na sua sistematização. O trabalho coletivo, neste caso, não é somente um artifício retórico do exercício sociológico desenvolvido, mas o resultado vivo de uma experiência acumulada de pesquisa e extensão envolvendo a realidade rural e camponesa.
} 
Em especial a realidade de atingidos pela Barragem de Acauã que já vivenciaram os impactos e violações daquela obra mas que também não conheciam uma grande parte do novo caminho das águas. Reconhecer e valorizar que o processo de pesquisa se dá no encontro de saberes e de experiências compartilhadas, portanto, foi uma das apostas do caminho das águas.

Desta forma, o planejamento das atividades se realizou em conjunto com lideranças do MAB, que já tinham alguns contatos prévios com pessoas que viviam às margens do Canal AcauãAraçagi e não eram necessariamente ligadas a nenhum movimento social organizado. A esses contatos iniciais foram somados outros, realizados pelo pesquisador a partir das lideranças de outros movimentos sociais do campo - em especial Comissão Pastoral da Terra e Movimento dos Trabalhadores Rurais Sem-Terra, CPT e MST, respectivamente.

Esta opção se revelou decisiva no processo da pesquisa empírica, pois todas as discussões e reflexões foram devidamente gravadas, inclusive as conversas realizadas no decorrer do percurso e geraram um acervo importante de materiais que estão em fase de sistematização - degravação e análise - e que, neste artigo, são apresentadas somente em linhas bastante gerais a partir de alguns achados da pesquisa de campo.

Ademais, realizou-se um planejamento para percorrer sempre que possível as margens do Canal até onde as construções estavam prontas, com inspiração nas experiências de cartografia social (ACSELRAD 2008), para documentar, georreferenciar e espacializar com o máximo de informações possíveis as situações vivenciadas por aqueles e aquelas que estavam "às margens" da obra.

Por outro lado, consideramos importante realizar entrevistas e compreender como estavam sendo planejadas as obras por parte dos órgãos de Estado, a fim de identificar discursos que permitissem compreender as problemáticas apontadas pelos "de cima". Assim, além desse percurso de quatro dias, foram realizadas diversas entrevistas um dia antes da viagem a campo na cidade de João Pessoa, em especial com servidores de Secretarias de Governo responsáveis pela obra, representantes de setores do agronegócio canavieiro (da Associação dos Plantadores de Cana da Paraíba - ASPLAN) e do Ministério Público Federal.

Como outro recurso metodológico utilizamos o aplicativo Locus Map para o georreferenciamento dos pontos visitados e realizamos a gravação do percurso feito de carro nos quatro dias de campo.

Já no primeiro dia de atividades em campo, iniciaram-se as atividades a partir da Barragem de Acauã, momento no qual os pesquisadores se encontraram com alguns dos sujeitos da pesquisa ligados ao MAB e realizaram-se as primeiras entrevistas, percorrendo, depois, um pequeno trecho do Canal logo após a tomada d'água. 
No segundo dia, partiu-se da Barragem de Acauã em direção à cidade de Campina Grande, seguindo pela Rodovia BR-230 até a chegar-se ao "ponto de encontro" das obras do Canal e realizando um percurso inverso pelas margens do Canal até as proximidades do Aqueduto na cidade de Mogeiro, momento no qual foi possível tomar alguns depoimentos e cartografar elementos importantes de análise sobre os impactos das obras tanto em áreas de agricultura familiar quanto de assentamentos da reforma agrária.

No terceiro dia, os objetivos da investigação foram percorrer os caminhos das obras do Canal após a margem direita da Rodovia BR-230, na qual foram novamente articuladas entrevistas com assentados da reforma agrária ligados ao MST e CPT, chegando até o canteiro de obras do Consórcio Acauã-Araçagi na cidade de Mari, a fim de agendar algumas entrevistas.

Já no quarto e último dia, privilegiou-se a realização de entrevistas com os agentes públicos e privados ligados ao empreendimento, no próprio canteiro de obras do Consórcio AcauãAraçagi, com o posterior regresso para a cidade de João Pessoa.

Em virtude da quantidade de materiais coletados dentre fotos, documentos e entrevistas ${ }^{10}$, escolhemos apresentar alguns achados deste material como resultado de uma primeira sistematização, no qual serão discutidas basicamente duas questões importantes: quais os objetivos da obra e a quem pode beneficiar?

Segundo as informações oficiais, trata-se da maior obra de construção civil do Estado. Reconhecida como a "transposição da Paraíba" dada a sua magnitude em termos de investimento é a maior obra do Programa de Aceleração do Crescimento (PAC) no Estado da Paraíba e a segunda maior obra hídrica do Nordeste. Está sendo executada por um Consórcio de empresas intitulado Consórcio Acauã-Araçagi, a partir de um projeto da Secretaria de Meio Ambiente, Recursos Hídricos e Ciência e Tecnologia (SEMARHCT), que realiza a sua supervisão técnica.

O Canal Acauã-Araçagi promete "beneficiar 600 mil habitantes e garantir irrigação em 16 mil hectares de terras", segundo as informações do Governo do Estado. Recentemente foi batizado com o nome do economista paraibano Celso Furtado e suas obras estão em estágio avançado, percorrendo cerca de 112 quilômetros em direção ao litoral norte da Paraíba. Em geral, o Canal foi construído a partir da desapropriação de áreas de 60 metros de cada lado da obra - podendo variar em algumas partes com 80 metros de cada lado - em todo o seu traçado, como se pode observar na imagem a seguir.

\footnotetext{
${ }^{10}$ Pedimos desculpas às leitoras e leitores pela extensão das citações, mas as consideramos muito importantes pelo fornecimento de elementos centrais para a pesquisa, que poderiam ser desdobrados e explicados parte a parte, mas que dadas as condições desta publicação serão apresentados como citações maiores e sem interrupções.
} 
Figura 2: Foto das obras de construção do Canal Acauã-Araçagi onde se observam as tubulações e a área desapropriada dos dois lados.

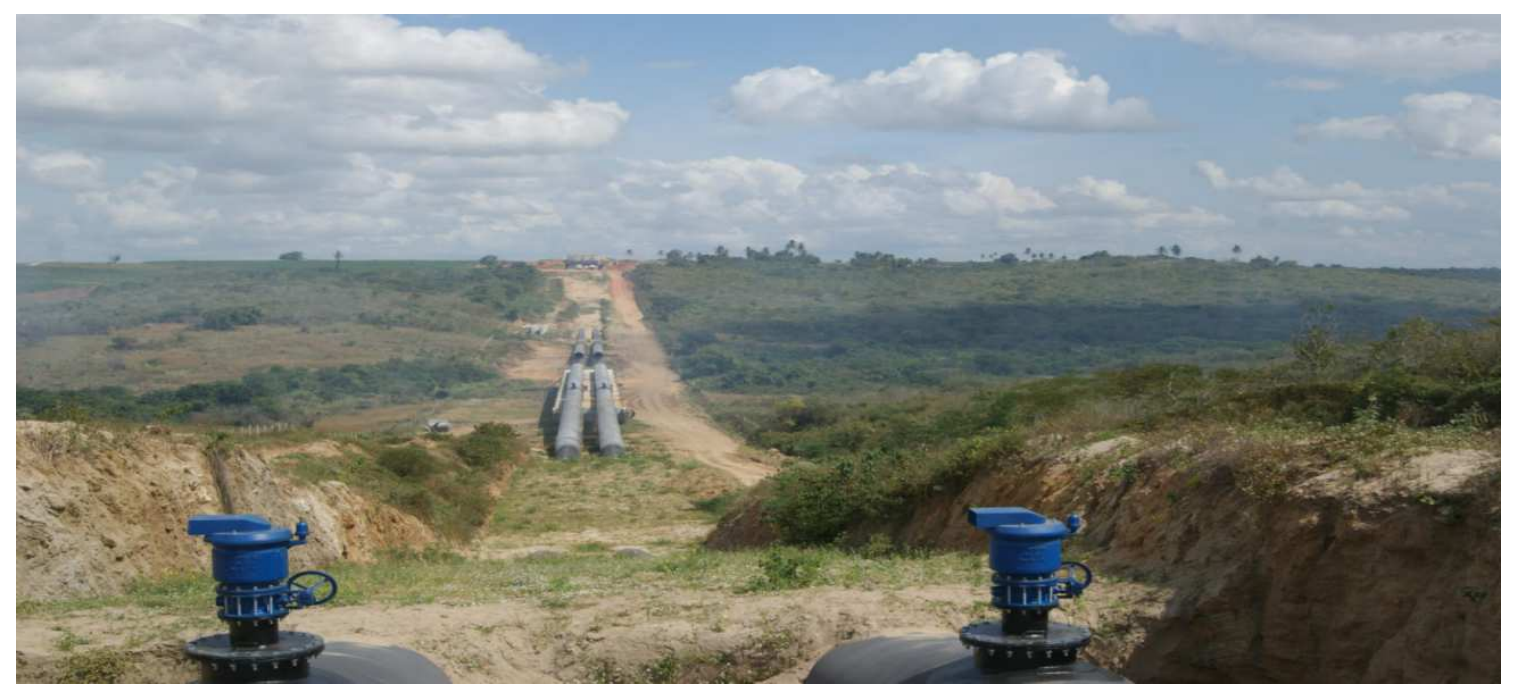

Fonte: Imagens feitas pela equipe de pesquisa (2018)

Na coleta de dados foi possível compreender melhor como o Governo do Estado pretende justificar seu anúncio acerca dos beneficiários: 600 mil beneficiários é o total da população de todos os municípios por onde, direta ou indiretamente, passam as obras do Canal Acauã-Araçagi. A partir da entrevista com um servidor da Secretaria de Agricultura e Pesca do Estado da Paraíba (SEDAP), compreendeu-se que a obra se desenvolve em três trechos úteis - dos quais dois trechos estavam em execução - com uma vazão inicial de $10 \mathrm{~m}^{3} / \mathrm{s}$.

O entrevistado esclareceu como foram realizados os cálculos para chegar à área de 16 mil hectares de potencial para irrigação: a vazão de $10 \mathrm{~m}^{3} / \mathrm{s}$ seria dividida entre a previsão de $2 \mathbf{~ m}^{3} / \mathbf{s}$ para abastecimento humano e $8 \mathrm{~m}^{3} / \mathrm{s}$ para agricultura irrigada, resultando no montante de possíveis 16 mil hectares para irrigação previstos na publicidade oficial. Chama a atenção neste dado informado, por óbvio, a diferença substancial apontada entre o que pretende ser destinado para abastecimento humano (inclusive para cidades que não tem sustentabilidade hídrica) e o que está previsto para ser utilizado na irrigação.

Outro dado importante mapeado na pesquisa de campo se relaciona com a projeção de quem poderá se beneficiar com as águas do Canal. É que, conjunta e paralelamente às obras, está sendo feito um grande levantamento de aptidão agrícola com base nos elementos solo e clima o chamado ZON (Zoneamento Pedoclimático) - conforme demonstra o mapa a seguir. Este mapa apresenta o canal e a chamada "área de influência" do canal: 
Figura 3: Zoneamento Pedoclimático (ZON)

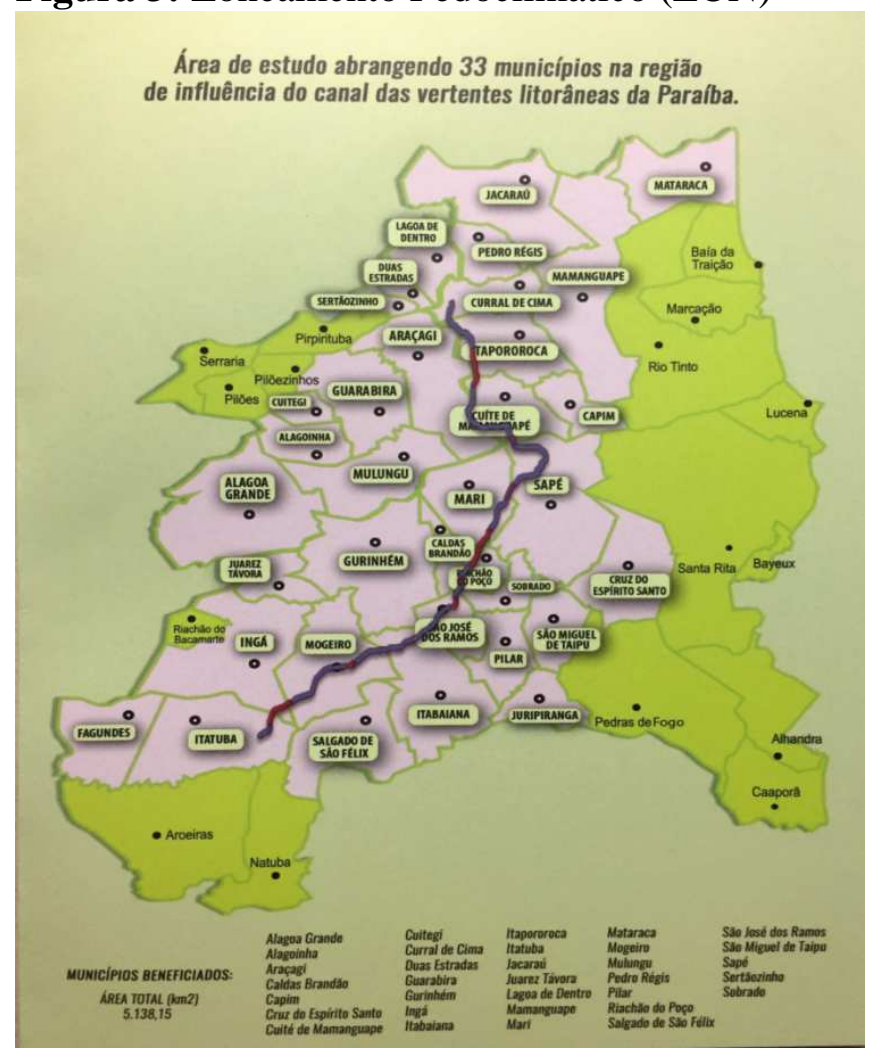

Fonte: Folder - Secretaria de Agricultura e Pesca do Estado da Paraíba (SEDAP), 2018.

Realizado pela Embrapa Solos em cooperação técnica com o Governo do Estado da Paraíba, este zoneamento se caracteriza por uma ampla pesquisa de campo a fim de levantar, na chamada "área de influência" do canal, cenários de produção agrícola. Perguntado sobre o motivo deste zoneamento específico, o entrevistado respondeu:

Entrevistado: então a gente espera desse trabalho que está sendo executado pela Embrapa Solos além dos mapas de solos que está sendo feito, os mapas de aptidão climática, né, para cenários de anos secos, anos regulares, anos chuvosos, né. Bem como manejo de média e alta tecnologia, certo? Para um leque de culturas, nós adotamos neste trabalho um leque de culturas que são as principais da região já, então nós temos o abacaxi que é forte na região, a cana-de-açúcar que é forte nessa região, o milho tá, o sorgo... então no caso, visando o desenvolvimento da produção de grãos também nessa região que tem um potencial fantástico, então com esse leque de culturas.

Entrevistadora: E a agricultura familiar, tá prevista?

Entrevistado: Assim, não tem um foco, o foco é agropecuária como um todo, o desenvolvimento das cadeias produtivas das culturas e aí, no contexto tá, independente do tamanho do produtor, se ele é mini, médio, grande, então...

Entrevistadora: Eu perguntei e eu vou te dizer porque... porque a agricultura familiar ela produz no varejo, é no varejo e na oportunidade de mercado, mas no varejo ela é biodiversificada então ela tem mandioca, milho, feijão... ela dá um sustento, ela tem uma dimensão que não é só do desenvolvimento regional mas também da reprodução da própria unidade familiar camponesa e é difícil você ver isso numa carta dessa, não é verdade?

Entrevistado: Sim, sim.

[...]

Entrevistadora: É porque eu só não consigo enxergar a agricultura familiar nessas aptidões. Entrevistado: mas assim a gente tem uma visão o seguinte: que a agricultura familiar ela tem esse contexto, essa característica, de diversificação de culturas né, o que é natural e o que é bom. mas a gente tem o conceito seguinte, de que é preciso melhorar a sua forma 
de trabalho em termos de tecnologia, até para que ele tenha melhores resultados econômicos... possa evoluir também, não ficar estagnado no tempo... então ao mesmo tempo, por exemplo, nós temos uma empresa que se instalou aqui, vou citar um exemplo, aqui em Mulungu, em que ele fez um plantio de uma área de milho em sequeiro, né, não irrigado, em que utilizando tecnologia ele chegou a obter 7 toneladas de grãos por hectare, e agricultores bem próximos da propriedade dele não estava chegando a 1000 quilos por hectare, então o que é que tá faltando aí? não é solo, não é clima, é tecnologia, para melhorar a sua capacidade de produção dentro daquela mesma área, sem precisar a área de produção...

(ENTREVISTA. Servidor da Secretaria de Agricultura e Pesca do Estado da Paraíba 2018)

Os dados prévios apontam, pois, que tanto as obras do Canal quanto o planejamento de médio prazo buscarão privilegiar e incentivar algumas culturas agrícolas ligadas ao agronegócio do agreste e litoral norte da Paraíba, como o caso do abacaxi, cana-de-açúcar e milho. Já o sorgo, cultura sem muita tradição na Paraíba e que tem uma relação direta com a produção de ração animal, parece estar sendo mapeado exatamente para a constituição de uma cadeia produtiva ligada à agroindústria avícola. Como se observa no seguinte trecho da entrevista, há uma "força da demanda" ligada à esta cadeia produtiva, citando um produtor de milho:

Entrevistador: Quem é esse produtor de milho?

Entrevistado: Ele tem uma área na Bahia, tem áreas em outros setores e ele veio aqui para Paraíba, ali entre Mulungu e Gurinhém e numas áreas lá ele plantou milho e teve um ano que não deu muito bem porque também choveu muito pouco, pegou sete anos de seca seguido aí que também não ajudou muito, mas a maioria do seus cultivos ele faz programado dentro daquela faixa de período invernoso daquela região, melhores índices pluviométricos, e de certa forma é um empreendimento que deu certo.

Entrevistadora: Mas ele não tem uma área pequena... é uma área boa?

Entrevistado: É, é uma área boa... teve ano que ele plantou 700 ha, teve um ano que ele chegou a implantar 2000 ha, então, assim, é uma área importante. E a demanda é grande. A demanda é grande.

Entrevistadora: Força de demanda.

Entrevistado: É, força da demanda. Nós temos bem próximo dessa área onde ele plantou a sede da Guaraves, que é o maior produtor de frango aqui do Estado da Paraíba, um dos maiores do Nordeste.

Entrevistadora: Ah, Milho com frango.

Entrevistado: Então, frango come milho, né.

Entrevistadora: Complexo milho-frango, tá bom.

Entrevistado: Ele com essa área, ele não atendia nem 30\% da demanda da Guaraves, então nós temos aí um potencial fantástico e um mercado aberto né, para expansão desse negócio. Bom, é, então essa é a visão que a gente tem com esse estudo, de melhorar também neste aspecto né, o agricultor familiar possa evoluir também neste aspecto, com conhecimento do solo que a gente vai ter nesse trabalho, conhecimento mais aprofundado do clima que a gente vai ter, e que a gente vai gerar mapas de toda essa região, a gente vai ter o conhecimento né, e a gente vai ter a tecnologia para que a assistência técnica possa assessorar melhor esse pessoal para avançar na sua produtividade.

Entrevistadora: Como você enxerga a integração desse agricultor familiar nesse esquema de desenvolvimento regional? Como você imagina um agricultor familiar de 2 hectares se integrando nessa força da demanda que você chama? Só se ele for integrado verticalmente por exemplo, pela Guaraves?

Entrevistado: Integrado pela Guaraves, através de organizar em cooperativas, associação de produtores, então o associativismo é fundamental neste desenvolvimento. 
Entrevistadora: Então você vê o agricultor familiar como um processo de integração no projeto geral?

Entrevistado: Sim, sem dúvida.

(ENTREVISTA. Servidor da Secretaria de Agricultura e Pesca do Estado da Paraíba 2018)

Aponta-se para um cenário que poderá ampliar os atingidos, agora não só pela construção da Barragem de Acauã e da construção do Canal, mas caso este planejamento ligado ao Zoneamento saia "do papel”. Não se trata somente das áreas que foram desapropriadas para construção do Canal - que já representaram diversos conflitos e impactos - mas de uma grande região que está sendo mapeada para produção agrícola às margens do Canal, provavelmente para instalação de perímetros irrigados e inclusive recebendo investimentos "de fora". Se nossa hipótese estiver correta, pode-se repetir, assim, o modelo que foi desenvolvido na região da Chapada do Apodi nos Estados do Ceará e Rio Grande do Norte que produziu e produz diversas violações (Brito 2016).

Enquanto esse planejamento está sendo realizado, um dos atingidos pela Barragem de Acauã (que reside exatamente na Comunidade Melancia, de onde se inicia o Canal), opina sobre as diferentes visões desses grandes projetos. Ele e sua família foram entrevistados em sua casa. Não só foram atingidos pela construção da Barragem de Acauã quanto sofreram com problemas posteriores no momento da construção do Canal e dizem que a construção do Canal piorou sua situação:

Entrevistado: A situação nossa não é fácil não. Você não vê perspectiva de nada. Tem quatro, cinco, seis famílias morando dentro de uma casa de placa.

Entrevistadora: Como é que pode isso né?

Entrevistado: Não tem pra onde crescer.

Entrevistadora: Mas piorou muito depois do Canal?

Entrevistado: Por causa do Canal piorou... aumentou né.

(...)

Mãe do entrevistado: Eles pensavam que ia dar muito trabalho para as famílias, mas, assim, deu... passou um ano e depois demitiu essas pessoas.

Entrevistadora: Quem que demitiu, não entendi.

Mãe do entrevistado: O Canal, pegaram muita gente aqui.

Entrevistadora: Para trabalhar, pra fazer o canal?

Entrevistado: Mas a conversa na verdade...

Entrevistadora: $\mathrm{O}$ canal ficou pronto todo mundo foi embora?

Mãe do entrevistado: E num ficou pronto não.

Entrevistado: Não. Foi depois que esfriou... Depois que esfria aquela pressão do povo, depois daquela audiência... contrataram muita gente daqui, contrataram daqui para justificar que era bom, depois, pé na tábua pra todo mundo.

Entrevistadora: Mandaram embora? E contrataram da onde?

Entrevistado: De outro lugar mais pra frente.

Entrevistador: Do caminho?

Entrevistado: Do caminho... que é pra justificar o canal pro povo se acalmar aí você contrata quem tá às margens.

Entrevistadora: Dizendo que o canal também ia dar emprego a muita gente.

Entrevistador: Vai dando emprego no caminho.

Entrevistado: Emprego de quinta categoria né, porque os empregos bom são do pessoal de fora... nunca tem daqui em emprego bom.

(ENTREVISTA. Atingido pela Barragem de Acauã - Comunidade de Melancia 2018) 
Nossa chave de interpretação, no entanto, apareceu em outra entrevista, desta vez com o "setor produtivo", ainda em João Pessoa. A expectativa do "setor produtivo" ligado à Cana-deaçúcar é descrita a seguir. Acerca do Canal há uma avaliação positiva pelo seu potencial, embora o próprio representante demonstre preocupações e dúvidas quanto às formas de gestão e uso das águas:

Entrevistado: a primeira coisa a gente tem que agradecer desse canal ter chegado, eu acho que todo mundo tem uma expectativa positiva, tá certo? porque numa região onde a gente precisa de um complemento, que nessa região não é totalmente árida, é uma região de transição, é uma região que tem anos bons, anos que não chove tão bem, e que com esse canal com certeza seria um complemento, de a gente ter uma segurança hídrica de poder produzir não só cana como outras culturas. (...) Agora o que a gente precisa ver com negócio de governo, é que quando pega gestão pública em perímetros irrigados, a maioria não tiveram muito sucesso... (...) Então a expectativa dos produtores é que esse canal sirva eh, não só que... que a gente sabe que a prioridade de um canal e de água até na própria lei já é bem clara, finalidade número um: consumo humano, número dois: consumo animal, e terceiro: outros fins. Então nos outros fins é onde vai entrar a questão da irrigação, tá certo? (...) hoje, se esse canal começasse a funcionar hoje não teria como funcionar, que ele ai ligar nada a coisa nenhuma... pelo menos a coisa nenhuma lá tá cheia, tá certo? Isso é uma ligação de Bacias aonde essa de Araçagi todos os anos, não sei se vocês sabem disso aí, tem conhecimento, todo ano ela fica com sua capacidade total. Todo ano ela sangra, tá certo? (...) se todo mundo já está com a tranquilidade que isso vai ser bom, muita gente tá em dúvida, porque você tem uma propriedade que tá lá, que foi dos seus avós a cem anos, nunca chegou nenhuma política pública, nenhum canal desses nem coisa nenhuma, na hora que chegar isso vai ser bom ou ruim? Todo mundo vai dizer que vai ser bom, ninguém sabe se é bom. Porque, me diga uma coisa, tá lá, aí faz uma desapropriação que passa com 60 metros desapropriado dentro da sua propriedade, se você não tiver acesso vai servir de quê isso aí pra você? Primeira pergunta, você vai poder usar essa água? como é que vai ser usada essa água? Então, a gestão dessa água é que é o principal, porque não adianta você gastar bilhões de reais, tá certo, ligar um canal desse e você ficar vendo a água passar sem poder usar. (...) Dinheiro no Brasil nunca faltou não, falta é o dinheiro que desvia prum lado pro outro, usa errado, mas dinheiro nunca faltou. Então a expectativa e o que a gente tem que ver é o uso dessa água, como é que vai ser usada... porque a gente sabe que tem período aqui, o Nordeste não é seco $100 \%$ não, aqui você tá vendo chovendo aqui hoje, esse litoral nosso aqui, durante todo o ano uns três, quatro meses tem uma estação chuvosa aqui abundante... Essa barragem de Araçagi vai continuar todo ano sangrando no mês de março, abril, qual seria o negócio racional e importante, uma iniciativa público-privada aonde os produtores pudessem usar esse canal para abastecer suas reservas, suas pequenas barragens, seus reservatórios, durante o período que não tivesse precisando, que tivesse sobrando água... (...) porque se não tiver cuidado a única coisa que vai servir é desviar essa água, uma parte dessa água, que ia descer direto aqui por Santa Rita e ia cair aqui em Cabedelo, se não tiver um uso racional dessa água, ela vai desviar um pouco e chegar lá embaixo no mar e passar por aqui e não deixar nada de produção...

(ENTREVISTA. Representante da Associação dos Plantadores de Cana da Paraíba 2018)

Observa-se, pois, a relação entre a construção do Canal e a expectativa - que queremos confirmar na tese - de uma espécie de segurança hídrica para o capital.

Em suma, não se trata, pois, de pensar a produção agrícola como exceção e necessidade de abastecimento como regra, mas de colocar a água e sua gestão em função das demandas do agronegócio, do presente e do futuro. 
A água, aqui, é vista como um complemento ou como um recurso hídrico, não como um bem comum. E a palavra gestão é entendida como ampliação do controle e/ou mercantilização para o seu uso ligado ao agronegócio através de parcerias público-privadas. A água é lida, aqui, como meio direto e indireto da acumulação capitalista e a sua gestão deve ser um facilitador deste processo.

\section{CONCLUSÕES INCONCLUSAS: O CAMINHO DAS ÁGUAS SE FAZ CAMINHANDO?}

O cenário acima descrito aponta, pois, para uma pesquisa ainda em curso e que está buscando comportar-se em termos teóricos e metodológicos com a dinâmica que a água exige: que vise à clarificar a complexidade e apontar as contradições muito mais do que "resolvê-las" em termos teóricos ou "fossilizá-las" em termos empíricos. Para estudos que envolvem a temática em termos jurídicos e sociológicos, o desafio ainda é muito grande e está só iniciando ${ }^{11}$.

Por outro lado, os relatos obtidos durante as entrevistas praticamente impõem uma abordagem multi ou interdisciplinar para sua análise. Ressaltamos este aspecto metodológico no nosso trabalho, que antes de tudo busca compreender as novas fases de acumulação capitalista e sua conflitualidade no tema das águas, tarefa que não é possível de realizar sem um profundo reconhecimento das limitações das áreas do conhecimento compartimentalizadas, o que aponta para uma contribuição metodológica importante que gostaríamos de ressaltar: todo conflito socioambiental ou territorial exige, por excelência, a interdisciplinaridade.

Outra dimensão importante trata da forma com que os dados anteriormente mapeados puderam ser parcialmente confirmados ou não pela atividade de campo realizada. Ao realizar este exercício entre teoria e prática se (re)definem parâmetros e se (re)constroem criativamente novos processos e projetos ancorados na realidade concreta, evitando que esta mesma realidade se transforme em um mero "por exemplo" para comprovar teorias previamente formuladas, ainda que estas teorias sejam importantes indicadores do processo dinâmico e complexo com o qual o capital, em termos internacionais, se expande e se acumula.

Mais propriamente, consideramos que a realidade necessita desta assunção conflituosa a fim de ser melhor compreendida. As contribuições do pensamento latino-americano que tem se debruçado em apontar tanto os cenários de luta e quanto de ampliação do despojo são, portanto,

\footnotetext{
${ }^{11}$ Importante apontar que o tratamento dos dados da pesquisa empírica foi só iniciado, motivo pelo qual as informações preliminares apresentadas aqui ainda poderão ser confirmadas ou negadas. São mais de 15 horas de entrevistas e 400 fotos, além de um conjunto de documentos importantes oficiais. Desta forma, nos contentamos em apresentar uma parte inicial deste processo para seguir com as inquietações que foram reformuladas a partir de nossa experiência empírica e que está em processo de sistematização.
} 
fundamentais para compreensão ampliada do que estamos vivendo. Trata-se, portanto, não somente de uma ampliação do conflito capital-trabalho, tal qual foi formulado ainda no século XIX, mas de uma multiplicidade de contradições interdependentes e determinadas pelo capital em relação à própria vida humana e não humana.

No caso do Nordeste e do semiárido, considerada região-problema por diversas abordagens (neo)desenvolvimentistas com base num determinismo geográfico ou climático, o desafio para pensar em alternativas é ainda maior. Isto porque lidamos não somente com as dificuldades inerentes aos conflitos socioambientais no Brasil em virtude da concentração de terras e do racismo ambiental. Mas também porque dentro da própria esquerda se produziu um discurso que intencionalmente ou não, pouco importa - reproduz as narrativas do capital.

Exatamente por isso encaramos que o caminho da pesquisa necessita fazer-se no caminho, assim como o caminho das águas que realizamos e que ainda irão, por certo, nos trazer diversos outros dados importantes para entender essa complexa e dialética teia de realidades hidroterritoriais a que não se quer somente compreender, mas transformar.

\section{REFERÊNCIAS:}

ACSELRAD, H. Cartografias sociais e território. Rio de Janeiro: IPPUR / UFRJ. 2008.

AGUILAR, R.G. Horizonte comunitario-popular: antagonismo y producción de lo común en América Latina. Puebla: Benemérita Universidad Autónoma de Puebla, Instituto de Ciencias Sociales y Humanidades “Alfonso Vélez Pliego”. 2015.

BARROS, J.N. O desencantamento das águas no Sertão: crenças, descrenças e mobilização social no Projeto de Transposição do Rio São Francisco. $1^{\mathrm{O}}$ ed. Rio de Janeiro: Letra Capital. 2017.

BORRAS JR, S.M. et al. Land grabbing in Latin America and the Caribbean. The Journal of Peasant Studies 39(3-4), p. 845-872. 2012. Disponível em: http://www.tandfonline.com/doi/full/10.1080/03066150.2012.679931 [Acessado: 17 janeiro 2019].

BRASIL. Relatório da Comissão Especial "Atingidos por Barragens”. Brasília-DF: Conselho de Defesa dos Direitos da Pessoa Humana (CDDPH). 2010. Disponível em: http://pfdc.pgr.mpf.mp.br/temas-de-atuacao/populacao-atingida-pelas-barragens/atuacao-dompf/relatorio-final-cddph [Acessado: 17 janeiro 2019].

BRITO, A.C.R. Águas para que(m): grandes obras hídricas e conflitos territoriais no Ceará. Curitiba: Editora CRV. 2016.

ENTREVISTA. Atingido pela Barragem de Acauã - Comunidade de Melancia. 2018.

ENTREVISTA. Representante da Associação dos Plantadores de Cana da Paraíba. 2018.

ENTREVISTA. Servidor da Secretaria de Agricultura e Pesca do Estado da Paraíba. 2018. 
IORIS, A.A.R. Da foz às nascentes: análise histórica e apropriação econômica dos recursos hídricos no Brasil. In: ALMEIDA, A. W. B. de org. Capitalismo globalizado e recursos territoriais: fronteiras da acumulação no Brasil contemporâneo. Rio de Janeiro, RJ, Brasil: Lamparina, p. 211-255. 2010.

LUXEMBURGO, R. A acumulação do capital: contribuição ao estudo econômico do imperialismo. São Paulo: Nova Cultural. Disponível em: http://ria.ufrn.br/handle/1/365 [Acessado: 17 janeiro 2019]. 1984.

MACIEL, C.A.A. e PONTES, E.T.M. Seca e convivência com o semiárido: adaptação ao meio e patrimonialização da caatinga no nordeste brasileiro. Rio de Janeiro, RJ, Brasil: Consequência. 2015.

MORAIS, H.B. de E QUANDO AS ÁGUAS “CHEGAM”? Barragem de Acauã, cercamento das águas e agrohidronegócio na Paraíba. In: Anais do VIII Simpósio Internacional de Geografia Agrária - SINGA. Curitiba: SINGA. 2017.

PORTO-GONÇALVES, C.W. Água não se nega a ninguém: a necessidade de ouvir outras vozes. Observatório Latino-americano de Geopolítica. Disponível em: http://www. geopolitica. ws/media_files/download/Wporto2. pdf. Acesso em 6(05), p. 2011. 2008.

RIBEIRO, A.M.M. et al. SOCIOLOGIA VIVA: Uma Proposta de construção de uma Rede Latinoamericana de Observatórios Fundiários e Núcleos de pesquisa e extensão focados em situações de conflito agroambientais rurais e nas lutas por terra. Retratos de Assentamentos 21(1), p. 71-96. Disponível em: http://retratosdeassentamentos.com/index.php/retratos/article/view/300 [Acessado: 21 janeiro 2019]. 2018.

TRUJILLO, M.L.N. Luchas por lo común: antagonismo social contra el despojo capitalista de los bienes naturales en México. $1^{\mathrm{O}}$ ed. Puebla: México, D.F: Benemérita Universidad Autónoma de Puebla, Instituto de Ciencias Sociales y Humanidades "Alfonso Vélez Pliego"; Bajo Tierra Ediciones. 2015.

TRUJILLO, M.L.N. Despojo múltiple sobre el tejido de la vida: impactos y resistencias socioambientales. Revista Textual (73). 2019. Disponível em:

http://chapingo.mx/revistas/textual/contenido.php?id_articulo=2496\&id_revistas=2\&id_revista_nu mero=259 [Acessado: 1 junho 2019].

VAINER, C. Águas para a vida, não para a morte. Notas para uma história do movimento de atingidos por barragens no Brasil. Revista Justiça ambiental e cidadania 1. 2004.

\section{AUTOR:}

\section{Hugo Belarmino de Morais}

Doutorando do Programa de Pós-Graduação em Sociologia e Direito da Universidade Federal Fluminense. Ex-Bolsista do Programa de Doutorado Sanduíche no Exterior - CAPES (PDSECAPES). Professor Assistente de Direito da Universidade Federal da Paraíba. Integrante do Observatório Fundiário Fluminense (OBFF - PPGSD) e do Instituto de Pesquisa em direitos e movimentos sociais (IPDMS). Advogado e assessor jurídico popular.

E-mail: hugobelmorais@gmail.com 